\title{
Longevity Analysis by Comparing the Overall Metabolism and Life Routine Regularity for Two Periods via GH-Method: Math-Physical Medicine
}

\author{
Hsu GC* \\ eclaireMD Foundation, USA
}

*Correspondence: Gerald C Hsu, eclaireMD Foundation, USA

Received on 07 July 2020; Accepted on 07 August 2020; Published on 21 August 2020

Copyright $\odot 2020$ Hsu GC. This is an open access article and is distributed under the Creative Commons Attribution License, which permits unrestricted use, distribution, and reproduction in any medium, provided the original work is properly cited.

\begin{abstract}
The author describes one of his hypothetical theories on the relationship between life longevity and overall metabolism, the macrosystem view, specifically the stress and daily life routine regularity, two micro-categories. He has spent 25,000 hover 7.5 years (2010-2019) to conduct research on metabolism, endocrinology, and chronic diseases, specifically diabetes. These big data analytics is based on 600,000 data over 2.5 years. His developed metabolism model has shed some light about the impact on his life longevity due to his overall metabolic changes, especially his stress level and life routine regularity. Having a strong lifestyle management leads into a good metabolic state, which then converts into a strong immunity to fight against three major disease categories, chronic diseases and complications (50\% of death), cancers (29\% of death), and infectious diseases (11\% of death), with the remaining $10 \%$ of non-diseases related to death cases. This is a logical way to achieve longevity which is the core of geriatrics.
\end{abstract}

Keywords: longevity, metabolism, stress, chronic diseases, lifestyle

Abbreviations: MI: metabolism index; GHSU: general health status unit

\section{Introduction}

This paper describes one of the author's hypothetical theories on the relationship between life longevity and overall metabolism, the macrosystem view, specifically the stress and daily life routine regularity, two micro-categories.

\section{Methods}

The author has spent $25,000 \mathrm{~h}$ over 7.5 years (2010-2019) to conduct research on metabolism, endocrinology, and 
chronic diseases, specifically diabetes.

In 2014, he established a mathematical model for metabolism which includes 4 output categories (weight, glucose, blood pressure, and lipids) and 6 input categories (food, water, exercise, sleep, stress, and life routine regularity). There are approximately 500 detailed elements included in these 10 categories. The "theoretical development" and a complete set of their interactive relationships would be an immense task, which includes calculations of 500 ! - this step is a massive undertaking without any significant benefit. Therefore, the author assigned various weighting factors to these elements and to seek important but partial interactions to investigate. By utilizing concepts and methods of topology, nonlinear algebra from mathematics, and finite element method from structural and mechanical engineering, he was able to define an approximated metabolic mathematical model with two newly defined variables, metabolism index (MI) and general health status unit (GHSU), where the GHSU is the 90-days moving average MI. This dynamic model can be expressed through these two variables to describe a person's health status at any moment of time.

\section{Results}

In 2017, from 1/1/2017-12/31/2017, Period A was the author's “best performed" period, i.e., lowest numerical scores (means the highest performance) on his 4 input categories, 6 output categories, MI, and GHSU.

Period B, from 1/1/2018-6/30/2019, is the "not-so-perfect performed" period, i.e., higher numerical scores (means poorer performance) on all categories. During Period B, the author attended at least 35 worldwide medical conferences to present over 70 medical papers. In addition, during this 18-month period, he wrote a total of 162 medical papers with 22 full-length articles published in various medical journals. In summary, during Period B, he overworked himself at the cost of damaging his overall health conditions, possibly shortening his life expectancy to some degree.

The figures below illustrate the lifestyle and medical conditions performance score comparison between the two periods graphically (Figure 1 and 2). He focused on four subjects: MI, GHSU, stress level, and daily life routine regularity. The figure shows both the data table of numerical comparison and a bar chart of performance percentages against baseline conditions (Figure 3). Specifically, 73.5\% is the baseline for both MI and GHSU, healthy if $<73.5 \%$ and unhealthy if $>73.5 \%$. He uses $70 \%$ as the best possible condition for stress level and $50 \%$ as the best possible condition for daily life routines.

Although his score of MI and GHSU has only increased (i.e., worsen) by $2 \%$ from Period A to Period B, most of his metabolic categories have the worst performance scores in Period B.

Most medical research have shown that majority of people, who lived long lives had a simple but routine lifestyle. Therefore, let us focus on the category of "life routine regularity". His performance score for this category has increased (i.e., worsen) by $2 \%$. More specifically, this increased numerical score (i.e., worsen performance) is the combined results from air flights, hotel meals, disturbance of food, exercise routines, weather changes, living environment changes, jetlag, and sleep pattern disruption.

It is quite interesting to find out that his stress level has no significant change, the comparison factor between Period $\mathrm{A}$ and $\mathrm{B}$ is $100 \%$ that is no change. This is probably due to the fact that medical research for him is his personal hobby unlike most working people, which is the ways and means to make a living with the purpose of gaining fame, power, or money. In addition, he has not suffered any stress from a "boss" and some "deadlines" from his research like other working people with normal jobs.

The list of daily life routine is shown in figure which has many items to factor in (Figure 4). Therefore, it is difficult to achieve a perfect score in this daily life routine category. His performance score in this category was $145 \%$ in Period $\mathrm{A}$ and $148 \%$ in Period B, which is an increase of $3 \%$. 


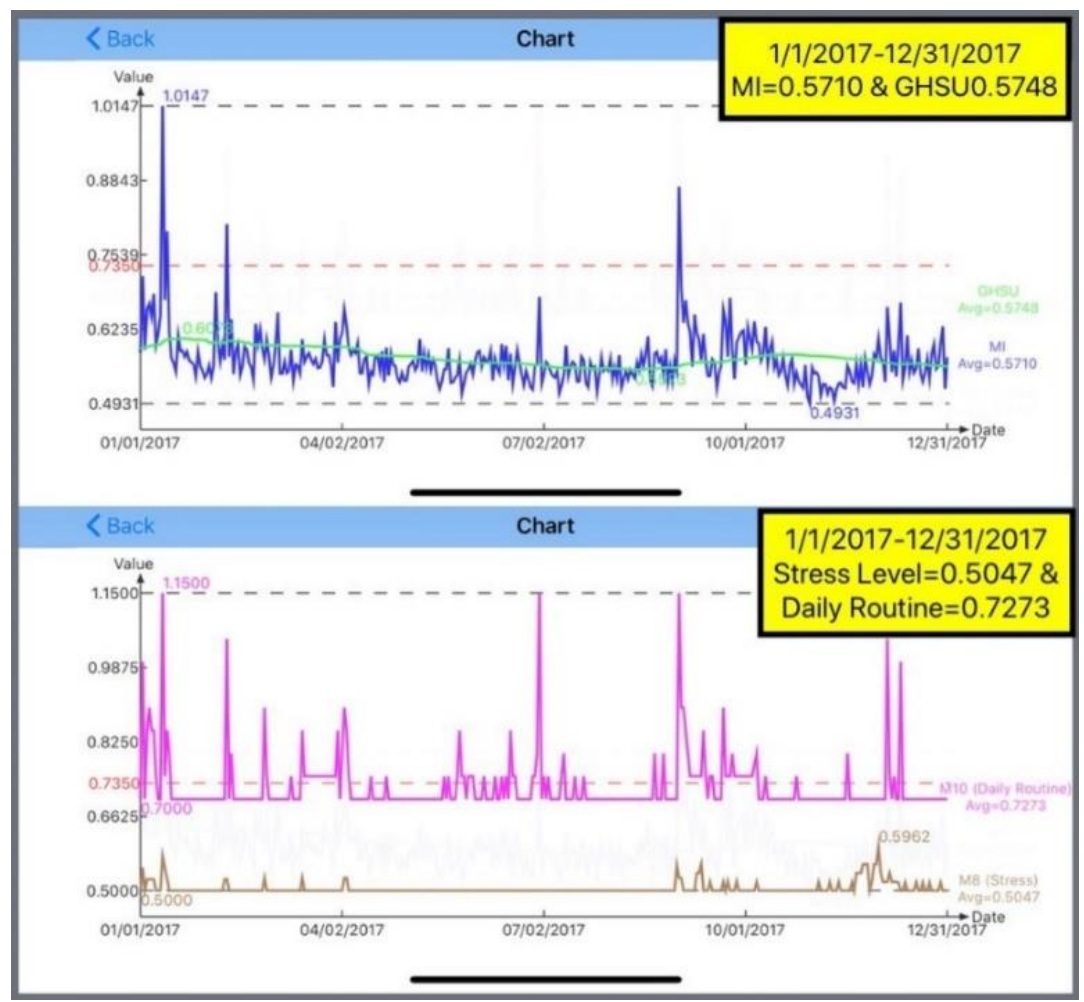

Figure 1: MI/GHSU and stress/daily routine of Period A (1/1/2017-12/31/2017).

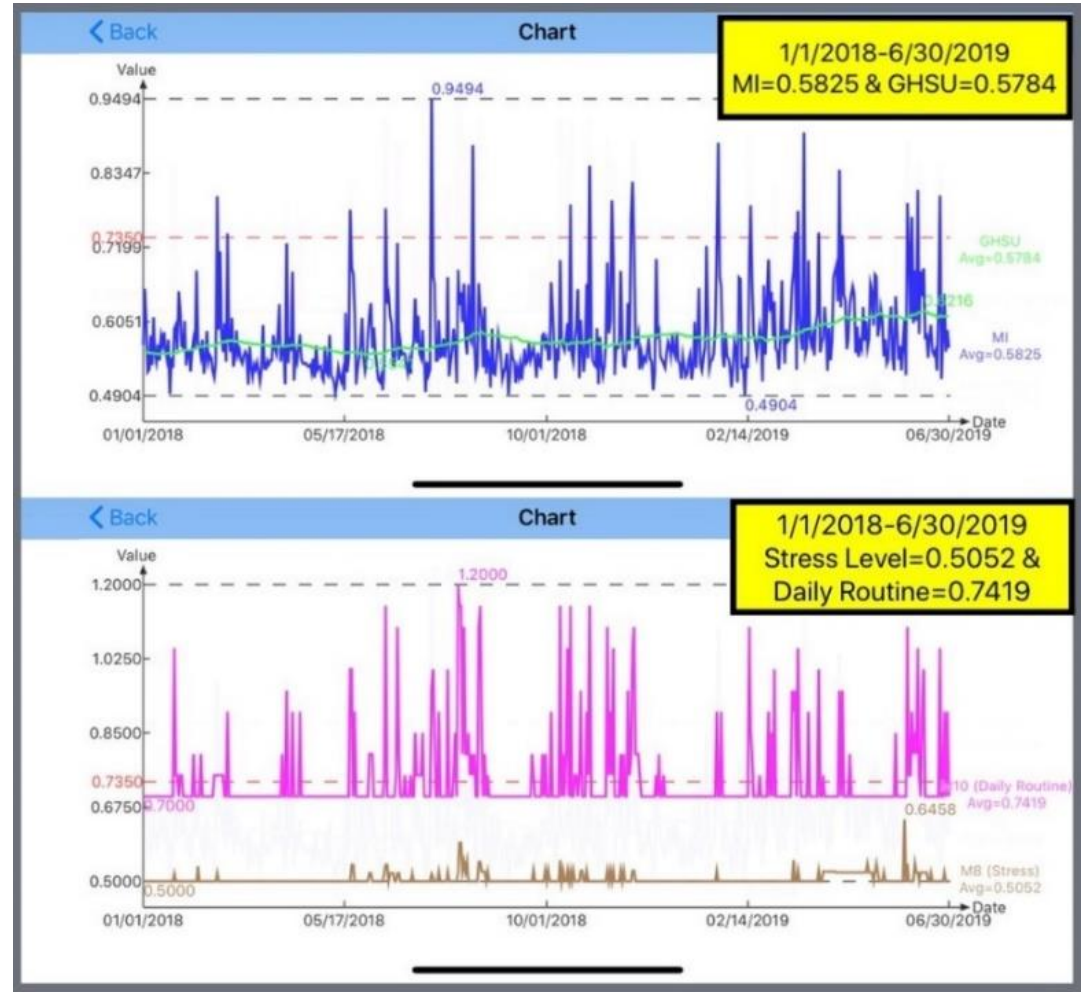

Figure 2: MI/GHSU and stress/daily routine of Period B (1/1/2018-6/30/2019). 


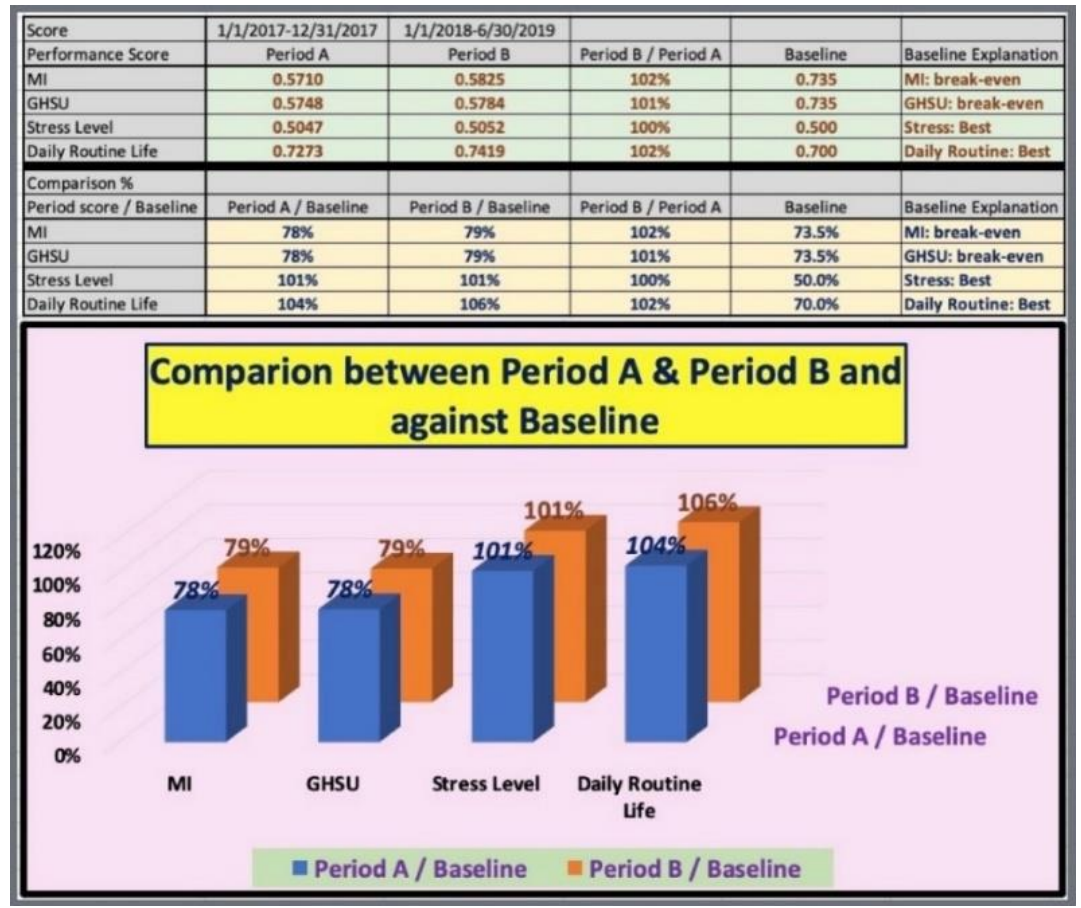

Figure 3: Comparison between Period A and Period B (MI, GHSU, stress, and daily routine).

\begin{tabular}{|c|c|c|}
\hline \multicolumn{3}{|l|}{ Q eclaireMD } \\
\hline \multicolumn{3}{|l|}{$\begin{array}{cc}\text { <Back } & 06 / 25 / 2020 \\
\mathrm{Ml}=0.7628 \quad \text { GHSU }=54.4 \% & \Omega\end{array}$} \\
\hline Food \& Meal & \multicolumn{2}{|c|}{ Daily Routine } \\
\hline \multicolumn{3}{|l|}{ Are the following items out-of-order? } \\
\hline Short Air Travel Today & Yes & No \\
\hline Long Air Travel Today & Yes & No \\
\hline Trauma Today & Yes & No \\
\hline Job \& Work & Yes & No \\
\hline Rest \& Leisure & Yes & No \\
\hline Exercise \& Fitness & Yes & No \\
\hline Food \& Meal & Yes & No \\
\hline Disease, Discomfort, Fatigue & Yes & No \\
\hline Hay Fever \& Allergy & Yes & No \\
\hline Weather \& Living Environment & Yes & No \\
\hline Jet Lag & Yes & No \\
\hline Sleep Pattern Disturbance & Yes & No \\
\hline Urination \& Bowel Movement & Yes & No \\
\hline Brain Exercise & Yes & No \\
\hline Meditation & Yes & No \\
\hline \multicolumn{3}{|l|}{ Environmental Factors for Cancer: } \\
\hline Alcohol Drinking & Yes & No \\
\hline Smoking & Yes & No \\
\hline
\end{tabular}

Figure 4: Daily life routine. 


\section{Conclusion}

These big data analytics is based on $~ 600,000$ data over 2.5 years. His developed metabolism model has shed some light about the impact on his life longevity due to his overall metabolic changes, especially his stress level and life routine regularity. Based on the findings from this specific analysis, the author has decided to change his lifestyle and work on a different approach to deliver and distribute his medical research results which does not involve a heavy travel schedule.

His metabolism model is an effective tool to investigate the subject of geriatrics and longevity. Moving from the inner circle toward the outside rings, the figure (Figure 5) depicts that lifestyle management leading into a good metabolic state, which then converts into a strong immunity to fight against three major disease categories, chronic diseases and complications (50\% of death), cancers (29\% of death), and infectious diseases ( $11 \%$ of death), with the remaining $10 \%$ of non-diseases related to death cases. This is a logical way to achieve longevity which is the core of geriatrics. References 1-4 provide more details regarding the author's work in this research area.

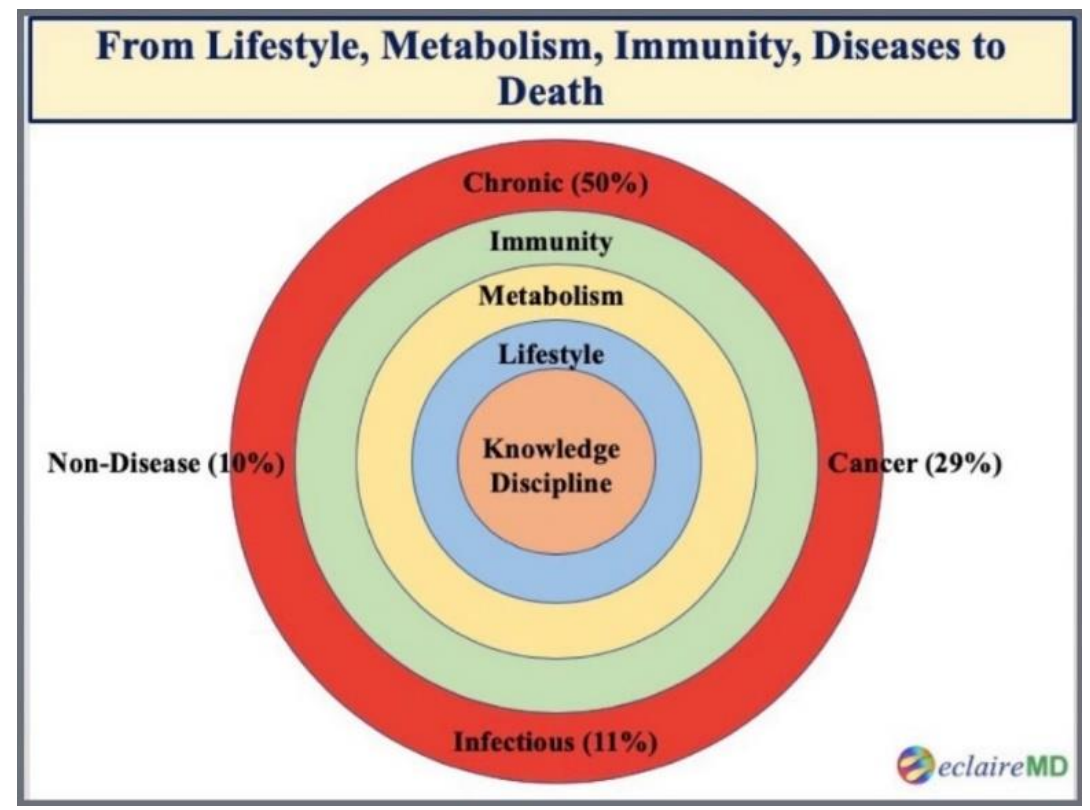

Figure 5: From lifestyle through metabolism, immunity, diseases and to death.

\section{References}

1. Hsu GC. Effective health age resulting from metabolic condition changes and lifestyle maintenance program. MOJ Gerontol Ger. 2020;5(3):92-94.

2. Hsu GC. A geriatric study of self-recovering diabetes conditions (GH-Method: Math-physical medicine). MOJ Gerontol Ger. 2020;5(4):105-108.

3. Hsu GC. Linkage among metabolism, immune system, and various diseases using GH-Method: Mathphysical medicine (MPM). Journal of Biotechnology and Immunology. 2020;2(3):1-5.

4. Hsu GC. Risk probability of having a metabolic disorder induced cancer using GH-Method: Math-physical medicine. Arch Infect Dis Therapy. 2020;4(2):1-3. 